\title{
Ghrelin attenuates intestinal ischemia/reperfusion injury in mice by activating the mTOR signaling pathway
}

\author{
HONGWEI ZHANG $^{1 *}$, ZHONGYI CUI $^{2 *}$, GUANGWEI LUO $^{3}$, JIAHENG ZHANG $^{4}$, \\ TAO MA ${ }^{1}, \mathrm{NA} \mathrm{HU}^{1}$ and TIANPEN CUI ${ }^{1}$ \\ ${ }^{1}$ Laboratory of Clinical Immunology, Wuhan No. 1 Hospital, Tongji Medical College, \\ Huazhong University of Science and Technology (HUST), Wuhan, Hubei 430022; ${ }^{2}$ Department of Biochemistry, \\ Guangdong Medical College, Zhanjiang, Guangdong 524023; Departments of ${ }^{3}$ Respiratory Medicine \\ and ${ }^{4}$ Surgery, Wuhan No. 1 Hospital, Tongji Medical College, Huazhong University of \\ Science and Technology (HUST), Wuhan, Hubei 430022, P.R. China
}

Received February 28, 2013; Accepted May 15, 2013

DOI: $10.3892 / \mathrm{ijmm} .2013 .1452$

\begin{abstract}
Intestinal ischemia/reperfusion (I/R) injury is a serious condition in intensive care patients, resulting in severe inflammation and remote organ damage. The activation of the mammalian target of rapamycin (mTOR)/p70 ribosomal S6 kinase (p70S6K) signaling pathway exerts protective effect against ischemia/reperfusion injury. Ghrelin, an orexigenic hormone, inhibits the release of pro-inflammatory cytokines, such as interleukin (IL)-1 $\beta$, tumor necrosis factor- $\alpha$ and IL-6. In this study, we investigated the effects of ghrelin on gut I/R injury and the regulation of the $\mathrm{mTOR} / \mathrm{p} 70 \mathrm{~S} 6 \mathrm{~K}$ signaling pathway following gut I/R injury in mice. C57BL/6 mice underwent superior mesenteric artery occlusion for $45 \mathrm{~min}$, followed by reperfusion for $4 \mathrm{~h}$. Ghrelin was administered at the onset of reperfusion. We assessed survival, organ injury variables, pro-inflammatory cytokine expression and observed the histological changes of the small intestine and lungs. Our results revealed that the administration of ghrelin inhibited the release of certain pro-inflammatory cytokines, reduced neutrophil infiltration, attenuated organ injury and improved survival following gut I/R injury. The administration of D-LysGHRP6, a specific ghrelin receptor antagonist, to a certain extent, counteracted the protective effects of ghrelin in gut
\end{abstract}

Correspondence to: Dr Tianpen Cui, Laboratory of Clinical Immunology, Wuhan No. 1 Hospital, Tongji Medical College, Huazhong University of Science and Technology (HUST), 215 Zhongshan Dadao, Wuhan, Hubei 430022, P.R. China

E-mail: tpcui616@gmail.com

*Contributed equally

Key words: ghrelin, intestinal ischemia/reperfusion, mammalian target of rapamycin/p70 ribosomal S6 kinase signaling pathway, D-Lys3-GHRP6, pro-inflammatory cytokines
I/R-induced organ injury and mortality. To determine whether the beneficial effects of ghrelin following gut I/R injury are associated with the mTOR/p70S6K signaling pathway, the phosphorylation levels of mTOR and p70S6K were detected by western blot analysis. Our results revealed that mTOR and p70S6K phosphorylation increased in the tissue from the small intestine and pulmonary tissue in the animals treated with ghrelin. These findings suggest that ghrelin attenuates organ injury following gut $\mathrm{I} / \mathrm{R}$ by promoting the activation of the mTOR/p70S6K signaling pathway.

\section{Introduction}

Acute intestinal ischemia is a serious abdominal emergency which is commonly observed in patients affected by trauma, burns and shock, as well as in those undergoing cardiovascular surgery and organ transplantation, resulting in a mortality rate as high as 60 to $80 \%(1-3)$. Transient ischemia results in biological and chemical changes which lead to intestinal mucosal damage and barrier dysfunction (4). Reperfusion can magnify the damage and even induce remote organ injuries and dysfunction through the generation of numerous pro-inflammatory cytokines and the activation of immune cells $(5,6)$.

The mammalian target of rapamycin (mTOR), a type of atypical serine/threonine kinase, integrates a variety of extracellular and intracellular signals, including growth factors, nutrients, energy depletion and stress (7). The activation of the 2 mTOR complexes, mTORC1 and mTORC2, regulates diverse functions, such as cell growth, proliferation, development, memory, longevity, angiogenesis, autophagy and innate, as well as adaptive immune responses (8-10). mTOR controls protein synthesis through the direct phosphorylation and inactivation of a repressor of mRNA translation, eukaryotic initiation factor 4E-binding protein 1 (4E-BP1), and through the phosphorylation and activation of p70 ribosomal S6 kinase (p70S6K), which in turn phosphorylates the ribosomal protein S6 $(8,11)$. Cytokines, growth factors, amino acids, insulin, or Toll-like receptor (TLR) ligands activate mTOR and increase the phosphorylation status of $4 \mathrm{E}-\mathrm{BP} 1$ and $\mathrm{p} 70 \mathrm{~S} 6 \mathrm{~K}$ in a 
rapamycin-sensitive manner $(8,11)$. Certain studies have shown that the activation of the mTOR/p70S6K signaling pathway exerts a protective effect against ischemia/reperfusion (I/R) injury (12-15).

Ghrelin, a 28-amino acid acylated peptide produced predominantly by the stomach, is an endogenous ligand for the growth hormone secretagogue receptor-1a (GHSR-1a) (16). Ghrelin has been shown to possess growth hormone-releasing properties and other endocrine and non-endocrine activities, reflecting central and peripheral GHSR-1a distribution (17-19). Previous studies have shown that ghrelin inhibits leptininduced pro-inflammatory cytokine [interleukin (IL)-1 $\beta$, tumor necrosis factor (TNF)- $\alpha$ and IL-6] expression by human $\mathrm{T}$ cells and monocytes (20) and suppresses nuclear factor (NF) $\kappa \mathrm{B}$ activation in human endothelial cells (21). It has been reported that ghrelin attenuates the formation of $\mathrm{I} / \mathrm{R}$-induced gastric lesions and other types of organ damage (22-25), with a decrease in TNF- $\alpha$ and IL-6 expression (26). mTOR activation has also been shown to inhibit the production of pro-inflammatory cytokines and to enhance the release of anti-inflammatory cytokines by blocking $N F-\kappa B$ activation and increasing signal transducer and activator of transcription 3 (STAT3) activity (27). Thus, in this study, we aimed to determine whether ghrelin ameliorates organ damage in a mouse model of intestinal I/R injury and to further elucidate the possible mechanisms behind its protective effects.

\section{Materials and methods}

Experimental model. Intestinal ischemia was induced in male C57BL/6J wild-type (WT) mice (16-22 g; Experimental Animal Center of Wuhan University, Wuhan, China) by clamping the superior mesenteric artery (SMA) for $45 \mathrm{~min}$ under general anesthesia using $0.5 \%$ pentobarbital sodium $(0.2 \mathrm{ml} / 10 \mathrm{~g})$ administered intraperitoneally (i.p.). The vascular clamp was released after $45 \mathrm{~min}$ to allow reperfusion. Upon the initiation of reperfusion, mice were resuscitated with $0.5 \mathrm{ml}$ saline (administered i.p.), after which treatment commenced. The mice were randomly divided into 4 experimental groups as follows: i) ghrelin group ( $n=10)$ : mice were administered (i.p.) recombinant murine ghrelin (no. 031-31, $12 \mathrm{nmol} / \mathrm{kg}$ in $0.5 \mathrm{ml}$ normal saline; Phoenix Pharmaceuticals, Inc. Belmont, CA, USA); ii) vehicle group $(n=10)$ : mice were administered (i.p.) $0.5 \mathrm{ml}$ normal saline; iii) ghrelin/D-Lys3-GHRP6 group $(\mathrm{n}=10)$ : mice were administered (i.p.) a mixture of ghrelin $(12 \mathrm{nmol} /$ $\mathrm{kg}$ in $0.25 \mathrm{ml}$ normal saline) and D-Lys3-GHRP6 (no. 031-22, $12 \mathrm{nmol} / \mathrm{kg}$ in $0.25 \mathrm{ml}$ normal saline; Phoenix Pharmaceuticals, Inc.); and iv) control (sham-operated) group $(n=10)$ : the animals underwent the same surgical procedure with the exception of SMA clamping. Four hours following reperfusion, the animals were anesthetized and blood (for serum) and tissue samples were harvested, stored immediately at $-80^{\circ} \mathrm{C}$ or soaked in $4 \%$ paraformaldehyde at $4^{\circ} \mathrm{C}$ until measurements were made. In addition, experiments for the observation of survival over the course of $24 \mathrm{~h}$ were performed ( $\mathrm{n}=11 /$ group). All experiments were carried out in accordance with the Guide for the Care and Use of Laboratory Animals (Institute of Laboratory Animal Resources) and were approved by the Institutional Animal Care and Use Committee of Wuhan No. 1 Hospital, Tongji Medical College (Wuhan, China).
Organ injury variables. Alanine aminotransferase (ALT), aspartate aminotransferase (AST), lactate dehydrogenase (LDH), creatinine and urea nitrogen levels in blood serum were determined using commercial assay kits (CicaLiquid ALT, YZB/JAP 1578-2009; CicaLiquid AST, YZB/JAP 1579-2009; CicaLiquid LDH J, YZB/JAP 1593-2009; CicaLiquid-N CRE, YZB/JAP 1599-2009; CicaLiquid-N UN, YZB/JAP 1590-2009; Kanto Chemical Co., Inc., Tokyo, Japan) and measured using a Biochemical Analyzer (ADVIA 2400; Siemens AG, Tarrytown, NY, USA).

Serum and tissue pro-inflammatory cytokines. TNF- $\alpha$, IL-1 $\beta$ and IL-6 levels were measured using specific mouse ELISA kits (nos. 88-7324-88, 88-7013-88 and 88-7064-88; eBioscience, Inc., San Diego, CA, USA) in serum, tissue from the small intestine and pulmonary tissue.

Tissue myeloperoxidase (MPO) assay. Small intestine and pulmonary MPO activity reflects the extent of neutrophil infiltration in the small intestine and lungs. MPO activity was evaluated using the MPO Colorimetric Activity Assay kit (Beijing Homa Biological Engineering Co., Ltd., Beijing, China) normalized to nanograms of protein and levels were measured using a Biochemical Analyzer (ADVIA 2400; Siemens). Protein concentration was measured using the BCA Protein assay kit (no. 23225; Pierce Protein Research Products; Thermo Fisher Scientific, Rockford, IL, USA).

Histopathological analysis. Samples from the small intestine (impaired areas) and lungs were fixed in $4 \%$ paraformaldehyde and embedded in paraffin. Tissues were sectioned and stained with hematoxylin and eosin. Histological scoring of the depth of tissue injury was performed according to the method described in the study by Chiu et al (28) with certain modifications: score 0 , no damage; score 1 , subepithelial space at villous tip; score 2, loss of mucosal lining of the villous tip; score 3, loss of less than half of the villous structure; score 4, loss of more than half of the villous structure; and score 5, transmural necrosis. Sections were evaluated blindly. Lung injury was analyzed for absent, mild, moderate, or severe injury (score 0-3) based on the presence of exudates, hyperemia/congestion, neutrophilic infiltrates, intra-alveolar hemorrhage/debris and cellular hyperplasia (29).

GHS-R and $m$ TOR/p70S6K western blot analysis. One hundred micrograms of protein from pulmonary and intestinal samples was fractionated on a 5-10\% SDS-PAGE gel and electrotransferred onto a $0.45-\mu \mathrm{m}$ polyvinylidene fluoride membrane. The blots were blocked with 5\% skimmed milk powder in Trisbuffered saline containing $0.1 \% \mathrm{v} / \mathrm{v}$ Tween-20 and incubated with $\beta$-actin (1-19) (1:800; sc-1616R; Santa Cruz Biotechnology, Inc., Santa Cruz, CA, USA), phospho-mTOR(Ser $\left.{ }^{2448}\right) \mathrm{mAb}$ (1:1,000; no. 5536), mTOR (7C10) mAb (1:1,000; no. 2983), phospho-p70S6K $\left(\mathrm{Thr}^{389}\right)$ antibody $(1: 1,000 ;$ no. 9234) all from Cell Signaling Technology, Inc. (Danvers, MA, USA) and anti-p70S6K mAb (1:1,000; 05-781R; Millipore, Billerica, MA, USA) in $5 \%$ bovine serum albumin-Tris-buffered saline with Tween-20 at $4^{\circ} \mathrm{C}$ overnight. The polyvinylidene fluoride membrane was then washed with Tris-buffered saline with Tween-20. Following incubation with anti-rabbit IgG 


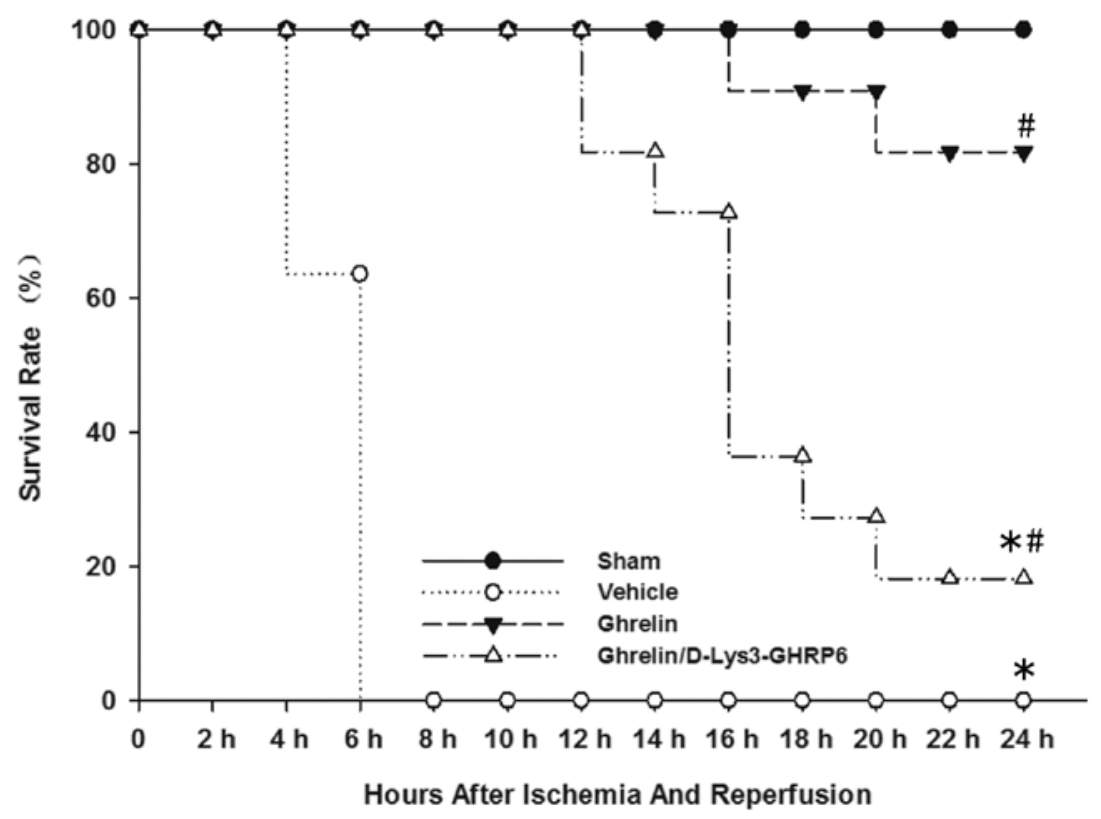

Figure 1. Twenty-four hour survival rate. Alterations in the survival rate at $24 \mathrm{~h}$ in the sham-operated animals (Sham), animals with ischemia/reperfusion injury treated with normal saline (Vehicle), ghrelin (Ghrelin) or a combination of ghrelin and D-Lys3-GHRP6 (Ghrelin/D-Lys3-GHRP6). Treatment with the vehicle $(0.5-\mathrm{ml}$ normal saline), ghrelin $(12 \mathrm{nmol} / \mathrm{kg})$ or a combination of ghrelin $(12 \mathrm{nmol} / \mathrm{kg})$ and D-Lys3-GHRP6 $(12 \mathrm{nmol} / \mathrm{kg})$ was administered intraperitoneally to the animals that underwent $45 \mathrm{~min}$ gut ischemia immediately after removing the microvascular clip. The animals were then allowed access to food and water and were observed for $24 \mathrm{~h}$. There were 11 animals in each group. Each point in the figure shows the mean survival rate at each time point. ${ }^{*} \mathrm{P}<0.05$ vs. sham-operated group; ${ }^{~} \mathrm{P}<0.05$ vs. vehicle group by Kaplan-Meyer log-rank test ( $\mathrm{n}=11 /$ group).

HRP-conjugated antibody (1:2,000; no. 7074; Cell Signaling Technology) in $5 \%$ bovine serum albumin-Tris-buffered saline with Tween-20 and washing with Tris-buffered saline with Tween-20, bands were detected using a chemiluminescent peroxidase substrate (no. 34079; ECL Plus; Thermo Fisher Scientific) and exposed on an image station (Kodak Image Station 4000MM).

Statistical analysis. Data were expressed as the means \pm SEM and compared by analysis of variance using one-way ANOVA and the Student-Newman-Keuls test. Survival analysis was carried out using the Kaplan-Meier log-rank test. A P-value $<0.05$ was considered to indicate a statistically signficant difference.

\section{Results}

Ghrelin improves survival following intestinal I/R injury. We performed survival analysis in mice receiving ghrelin at the onset of reperfusion and compared them with control mice treated with normal saline. We also established a group which was administered ghrelin and D-Lys3-GHRP-6. All the control mice died within $24 \mathrm{~h}$ (median survival time, $5.9 \mathrm{~h}$; 95\% confidence interval, 5.2-6.6) (Fig. 1). Nine of the 11 mice treated with ghrelin, however, remained alive $24 \mathrm{~h}$ following gut I/R injury (median survival time, $22.9 \mathrm{~h} ; 95 \%$ confidence interval, 21.2-24.7) (Fig. 1). Among these, 7 mice survived for $>1$ week (data not shown). Two of the 11 animals administered ghrelin and D-Lys3-GHRP-6 remained alive $24 \mathrm{~h}$ following gut I/R injury (median survival time, $17.3 \mathrm{~h} ; 95 \%$ confidence interval, 14.6-20) (Fig. 1).
Ghrelin attenuates multiple organ damage following intestinal I/R injury. Gut I/R caused microscopic intestinal damage, such as mucosal destruction, loss of villi and epithelial cell apoptosis, hemorrhaging and infiltration of inflammatory cells (Fig. 2B). Treatment with ghrelin significantly improved these microscopic alterations (Fig. 2C). Similarly, lung injury characterized by the disruption of lung architecture, extravasation of red blood cells, and accumulation of inflammatory cells was present in the I/R-vehicle treated animals (Fig. 3B). The ghrelin-treated mice displayed a marked reduction in the number of infiltrating inflammatory cells and an improvement in lung architecture (Fig. 3C). In the gut and lungs, tissue injury was slightly ameliorated in the mice treated with ghrelin and D-Lys3-GHRP6 (Figs. 2D and 3D). To evaluate remote organ injury at the biochemical level, we assayed the serum activities of AST, ALT, LDH, creatinine and urea nitrogen. Compared with the sham-operated animals, serum ALT, AST, LDH, creatinine and urea nitrogen levels in the animals with I/R injury in the vehicle-treated group increased by 13.79-, 8.58-, 5.57-, 4.12- and 5.19-fold, respectively $(\mathrm{P}<0.05)$ (Fig. 4). The administration of ghrelin decreased ALT, AST, LDH, creatinine and urea nitrogen levels by 59.7, 67.4, 50.6, 63.9 and $71.6 \%$, respectively $(\mathrm{P}<0.05)$ (Fig. 4) compared with the vehicle-treated group. When the animals with I/R injury were simultaneously administered ghrelin and its antagonist, D-Lys3-GHRP6, the plasma levels of ALT, AST, LDH, creatinine and urea nitrogen decreased by $48,34.1,29.6,19.5$ and $39.6 \%$, respectively $(\mathrm{P}<0.05)$ (Fig. 4).

MPO activity is an indicator of neutrophil infiltration. As demonstrated in Fig. 5, gut I/R induced a significant increase in intestinal and pulmonary MPO activity in the vehicle-treated 

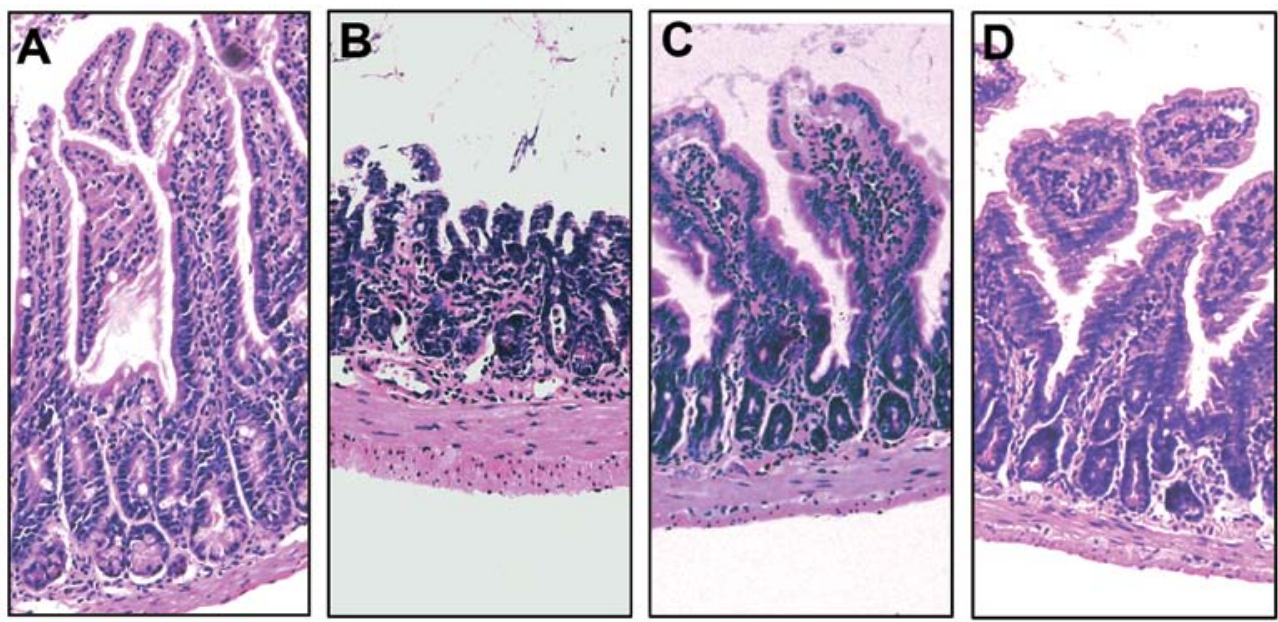

Figure 2. Photomicrograph showing morphological alterations of the small intestine. (A) Photomicrograph of a section of the small intestine from a shamoperated mouse; (B) photomicrograph of a section of the small intestine from a mouse with gut ischemia/reperfusion injury at $4 \mathrm{~h}$ after reperfusion, treated with the vehicle; (C) photomicrograph of a section of the small intestine from a mouse with gut ischemia/reperfusion injury at $4 \mathrm{~h}$ after reperfusion, treated with ghrelin; (D) photomicrograph of a section of the small intestine from a mouse with gut ischemia/reperfusion injury at $4 \mathrm{~h}$ after reperfusion, treated with a combination of ghrelin and D-Lys3-GHRP6. Original magnification, $x 100$. Data are expressed as the means \pm SE ( $n=5 /$ group) and compared by one-way analysis of variance (ANOVA) and the Student-Newman-Keuls test. ${ }^{*} \mathrm{P}<0.05$ vs. sham-operated group; ${ }^{*} \mathrm{P}<0.05$ vs. ischemia/reperfusion + vehicle group.
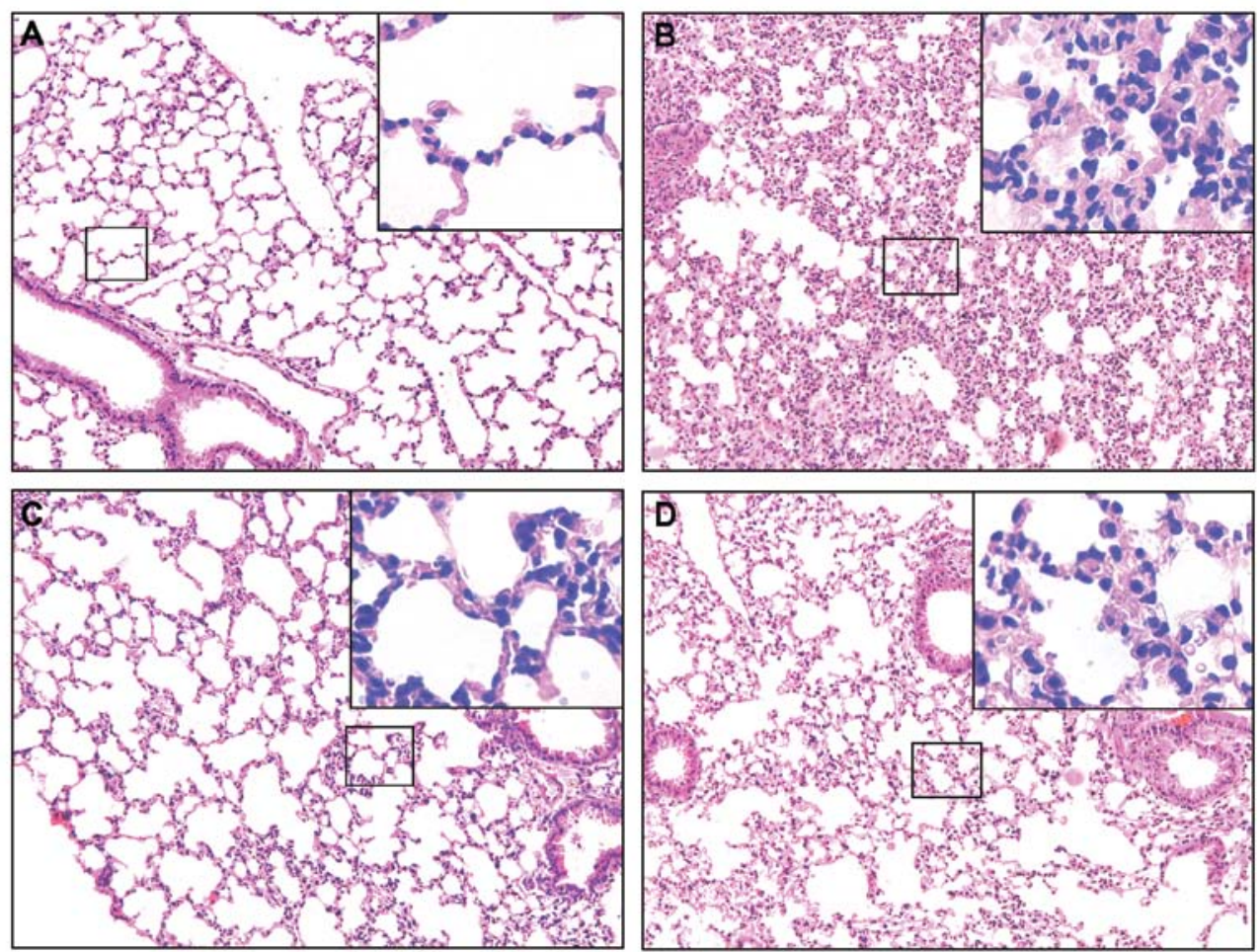

Figure 3. Photomicrograph showing morphological alterations of the lung. (A) Photomicrograph of a pulmonary section from a sham-operated mouse; (B) photomicrograph of a pulmonary section from a mouse with gut ischemia/reperfusion injury at $4 \mathrm{~h}$ after reperfusion, treated with the vehicle; (C) photomicrograph of a pulmonary section from a mouse with gut ischemia/reperfusion injury at $4 \mathrm{~h}$ after reperfusion, treated with ghrelin; (D) photomicrography of a pulmonary section from a mouse with gut ischemia/reperfusion injury at $4 \mathrm{~h}$ after reperfusion, treated with a combination of ghrelin and D-Lys3-GHRP6. Insets: images of boxed areas at higher magnification. Original magnification, $x 100$; insets, $x 400$. Data are expressed as the means $\pm \mathrm{SE}$ ( $\mathrm{n}=5 / \mathrm{group}$ ) and compared by one-way analysis of variance (ANOVA) and the Student-Newman-Keuls test: ${ }^{*} \mathrm{P}<0.05$ vs. sham-operated group; ${ }^{\#} \mathrm{P}<0.05$ vs. ischemia/reperfusion + vehicle group.

mice as compared with the sham-operated animals. Treatment with ghrelin significantly inhibited the increase in intestinal (Fig. 5A) and pulmonary (Fig. 5B) MPO activity following gut $\mathrm{I} / \mathrm{R}$. These results demonstrate that ghrelin attenuates the influx of neutrophils into the gut and lungs following gut I/R injury.
Ghrelin suppresses pro-inflammatory responses following gut I/R injury. Pro-inflammatory cytokines play an important role in the injury of remote organs following gut $\mathrm{I} / \mathrm{R}$. To investigate whether the cytokines, TNF- $\alpha$, IL- $1 \beta$ and IL- 6 , were affected by treatment with ghrelin, we determined their expression 

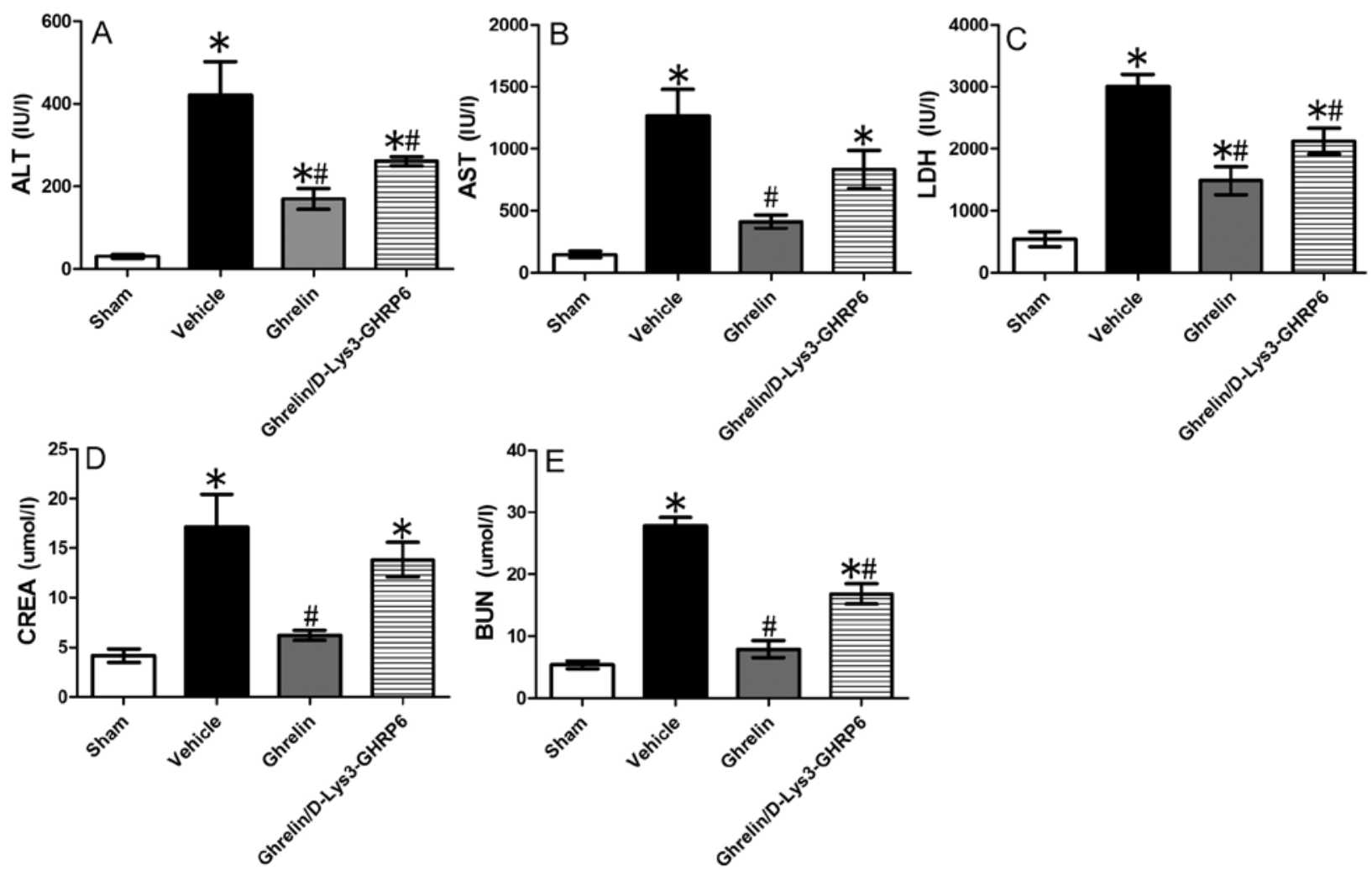

Figure 4. Attenuation of organ injury by ghrelin following intestinal ischemia-reperfusion (I/R). The superior mesenteric artery was occluded for 45 min, followed by $4 \mathrm{~h}$ of reperfusion. Serum levels of (A) alanine aminotransferase (ALT), (B) aspartate aminotransferase (AST), (C) lactate dehydrogenase(LDH), (D) creatinine (CREA) and (E) blood urea nitrogen (BUN) were measured $4 \mathrm{~h}$ after reperfusion. Data are expressed as the means $\pm \mathrm{SE}$ (n=5/group) and compared by one-way analysis of variance (ANOVA) and the Student-Newman-Keuls test: ${ }^{*} \mathrm{P}<0.05$ vs. sham-operated group; ${ }^{\#} \mathrm{P}<0.05$ vs. I/R + vehicle group.
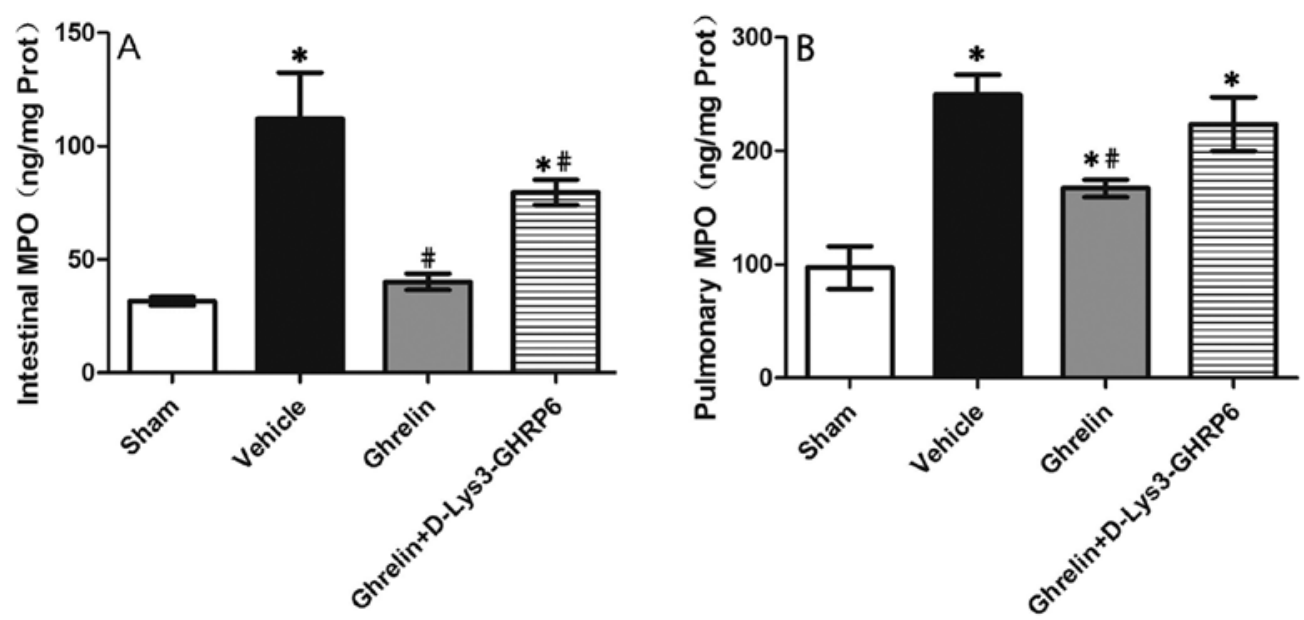

Figure 5. Myeloperoxidase (MPO) activity in tissues. Alterations in (A) intestinal and (B) pulmonary MPO activity in the sham-operated animals (Sham) and animals with ischemia/reperfusion (I/R) injury treated with normal saline (Vehicle), ghrelin (Ghrelin) or a combination of Ghrelin and D-Lys3-GHRP6 (Ghrelin/D-Lys3-GHRP6) at $4 \mathrm{~h}$ after reperfusion. Data are presented as the means $\pm \mathrm{SE}$ ( $\mathrm{n}=5 /$ group) and compared by one-way analysis of variance (ANOVA) and the Student-Newman-Keuls test: ${ }^{*} \mathrm{P}<0.05$ vs. sham-operated group; ${ }^{"} \mathrm{P}<0.05$ vs. I/R + vehicle group.

levels in the blood, intestine and lungs. We found that the cytokine levels in the serum increased significantly following intestinal I/R injury (TNF- $\alpha$ by 14.5 -fold, IL-1 $\beta$ by 27.1 -fold and IL- 6 by 20.4 -fold), while the administration of ghrelin markedly reduced the pro-inflammatory response (by 75.3 , 90.2 and $71.9 \%$, respectively) (Fig. 6A-C). We also measured TNF- $\alpha$, IL- $1 \beta$ and IL- 6 production in the small intestine and lungs using ELISA. We observed similar suppressive effects of ghrelin on cytokine levels in tissue from the small intestine (Fig. 6D-F), as well as in pulmonary tissue (Fig. 6G-I). As shown by our results, the levels of TNF- $\alpha$, IL-1 $\beta$ and IL- 6 significantly decreased in the tissue from the small intestine (by 65.3, 62.7 and 53\%) (Fig. 6D-F) and lung tissue (by 50, 61.7 and $51.1 \%$ ) (Fig. 6G-I) following treatment with ghrelin. 

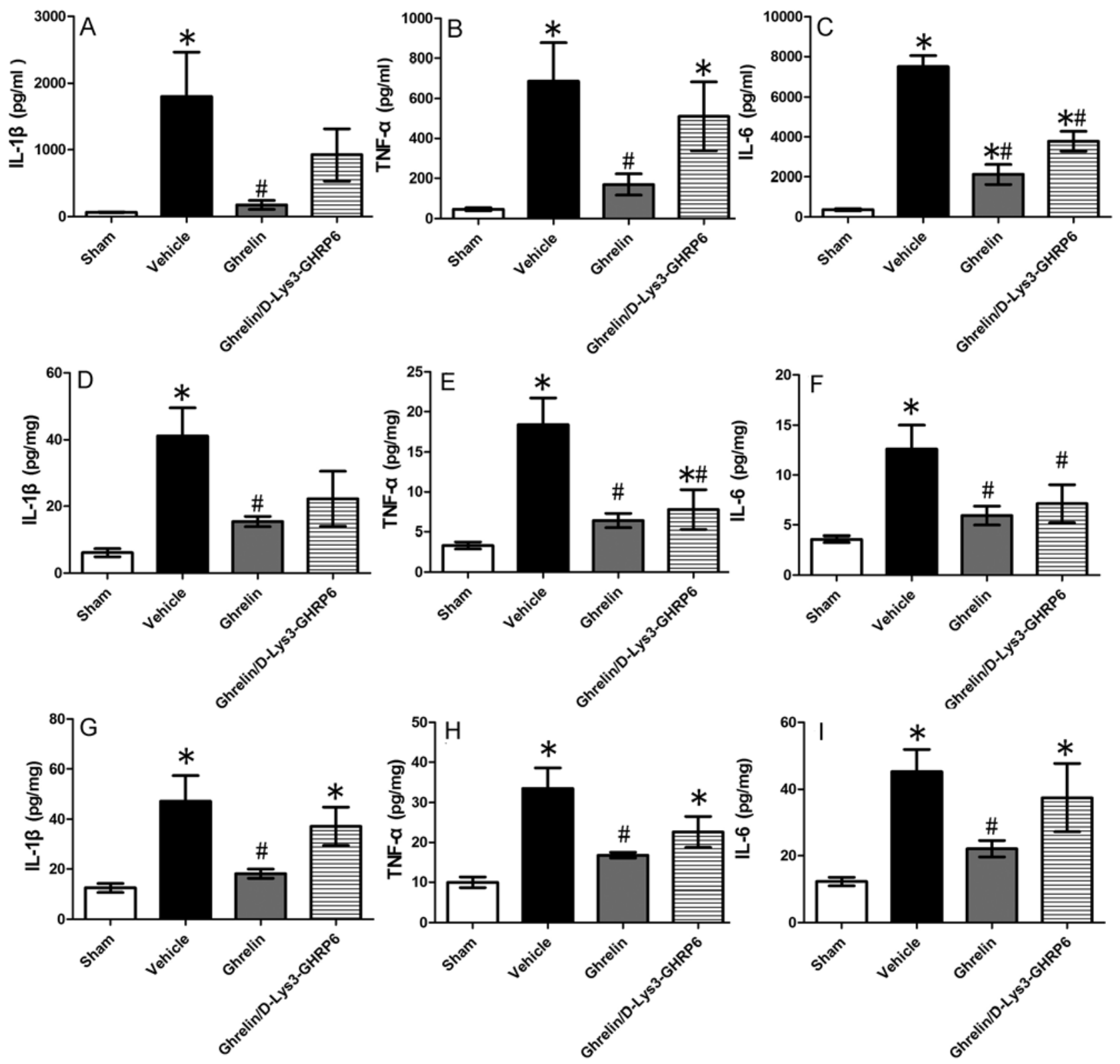

Figure 6. Pro-inflammatory cytokine levels in serum and tissues. Alterations in the levels of interleukin (IL)-1 $\beta$, tumor necrosis factor (TNF)- $\alpha$ and IL-6 in the serum in the tissue from the small intestine and pulmonary tissue in the sham-operated animals (Sham), animals with ischemia/reperfusion (I/R) injury treated with normal saline (Vehicle), ghrelin (Ghrelin) or a combination of Ghrelin and D-Lys3-GHRP6 (Ghrelin/D-Lys3-GHRP6) at $4 \mathrm{~h}$ after reperfusion. (A) IL-1 $\beta$ levels in serum; (B) TNF- $\alpha$ levels in serum; (C) IL-6 levels in serum; (D) IL-1 $\beta$ levels in tissue from small intestine; (E) TNF- $\alpha$ levels in tissue from small intestine; (F) IL-6 levels in tissue from small intestine; (G) IL-1 $\beta$ levels in pulmonary tissue; (H) TNF- $\alpha$ levels in pulmonary tissue; (I) IL-6 levels in pulmonary tissue. Data are presented as the means $\pm \mathrm{SE}$ ( $\mathrm{n}=5$ /group) and compared by one-way analysis of variance (ANOVA) and the Student-Newman-Keuls test: ${ }^{*} \mathrm{P}<0.05$ vs. sham-operated group; ${ }^{\#} \mathrm{P}<0.05$ vs. $\mathrm{I} / \mathrm{R}+$ vehicle group.

Antagonistic effect of D-Lys3-GHRP-6 on ghrelin-mediated tissue protection following intestinal I/R injury. D-Lys3GHRP-6 is a ghrelin receptor antagonist. It was used for further confirmation of the protective effects of ghrelin in our experimental model. We observed that the levels of the proinflammatory cytokines, TNF- $\alpha$, IL- $1 \beta$ and IL- 6 , in the lungs of the animals treated with D-Lys3-GHRP6 did not differ significantly from those in the animals in the vehicle-treated group. The levels of TNF- $\alpha$, IL- $1 \beta$ and IL- 6 in pulmonary tissue decreased by $32.6,21.5$ and $17.2 \%$, respectively in the group treated with D-Lys3-GHRP6 compared with the vehicle-treated group (Fig. 6G-I). As shown in Fig. 6A-C, the levels of TNF- $\alpha$, IL-1 $\beta$ and IL- 6 in the serum decreased by
25.7, 48.7 and $49.9 \%$, respectively in the group treated with D-Lys3-GHRP6 compared with the vehicle-treated group. In the tissue from the small intestine, the TNF- $\alpha$, IL- $1 \beta$ and IL-6 levels were reduced by $57.9,46$ and $43.5 \%$, respectively in the group treated with D-Lys3-GHRP6 compared with the vehicle-treated group (Fig. 6D-F). However, the levels of IL-6 in the serum and tissue from the small intestine, as well as the TNF- $\alpha$ levels in the tissue from the small intestine markedly decreased. We hypothesized that D-Lys3-GHRP6 has a partial inhibitory effect on GHSR-1a in organisms.

Ghrelin promotes the activation of the MTOR signaling pathway in the small intestine and lungs. In order to deter- 


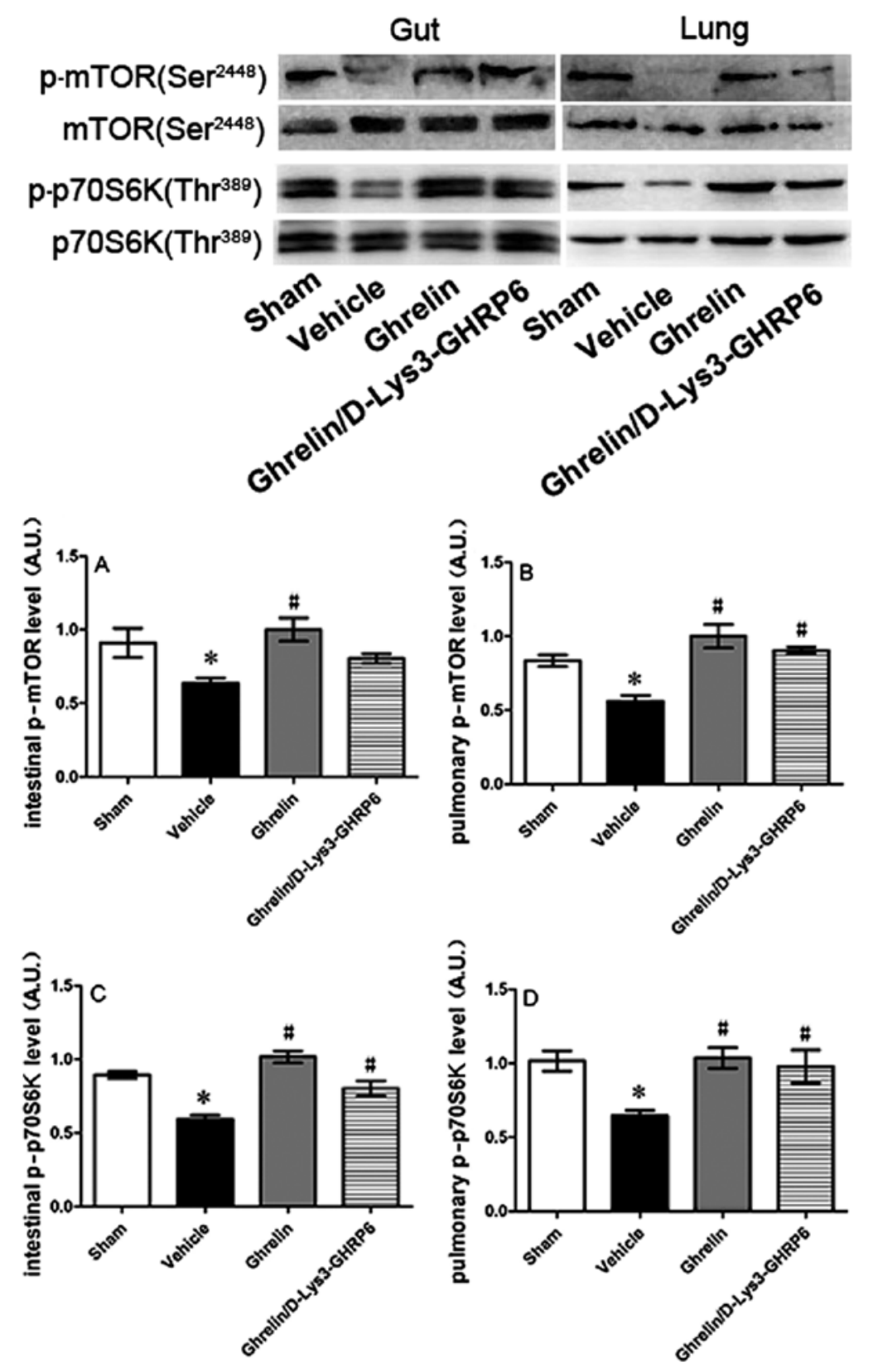

Figure 7. mTOR and p70S6K phosphorylation in tissue from the small intestine and pulmonary tissue. Western blot analysis of phosphorylated mTOR (p-mTOR) and phosphorylated p70S6K (p-p70S6K) in tissue from the small intestine and pulmonary tissue from the sham-operated animals (Sham), animals with ischemia/ reperfusion (I/R) injury treated with normal saline (Vehicle), ghrelin (Ghrelin) or a combination of Ghrelin and D-Lys3-GHRP6 (Ghrelin/ D-Lys3-GHRP6) at $4 \mathrm{~h}$ after reperfusion. Densitometric analysis is represented as an arbitrary unit (AU). Data are represented as the means \pm SE ( $\mathrm{n}=5 / \mathrm{group}$ ) and compared by one-way analysis of variance (ANOVA) and the Student-Newman-Keuls test: ${ }^{*} \mathrm{P}<0.05$ vs. sham-operated group; ${ }^{\text {}} \mathrm{P}<0.05$ vs. I/R + vehicle group.

mine whether ghrelin mediates the activation of the mTOR signaling pathway, we extracted protein from the injured small intestine and lungs and detected phosphorylated mTOR and p70S6K levels by western blot analysis. mTOR and p70S6K phosphorylation increased in the tissue from the small intestine and pulmonary tissue in the animals treated with ghrelin compared with the vehicle-treated group (Fig. 7).

\section{Discussion}

Intestinal $\mathrm{I} / \mathrm{R}$ injury is a serious complication in a variety of pathological conditions and surgical procedures, including sepsis, strangulated bowel, vascular surgery and hemorrhagic shock (30). The activation of immune cells adjacent to the huge endothelial cell surface area of the intestinal microvasculature produces initially local and then systemic inflammatory responses, which lead to severe tissue damage (26).

Ghrelin is an endogenous ligand for GHSR-1a (16), and GHSR-1a expression is present in the brain stem, pituitary gland, hypothalamus, heart, blood vessels, lungs, stomach, pancreas, intestines, kidneys and adipose tissue (31-33). Therefore, ghrelin plays various physiological roles in both the central nervous system and the periphery (19), such as the regulation of pituitary hormone secretion, feeding, energy homeostasis, 
gastrointestinal function, as well as in the cardiovascular and immune system (34-36). In a previous study, Wu et al (26) showed that plasma levels of ghrelin were significantly reduced and that the administration of exogenous ghrelin attenuated local and remote organ injury following gut $\mathrm{I} / \mathrm{R}$ in rats. In the present study, we established a mouse model of intestinal I/R (i.e., superior mesenteric artery occlusion) and found that the indicators of tissue injury (MPO activity) and organ dysfunction (ALT, AST, LDH, creatinine and urea nitrogen levels) were significantly decreased in the ghrelin-treated mice following gut I/R. The levels of the pro-inflammatory cytokines, TNF- $\alpha$, IL- $1 \beta$ and IL- 6 , were also decreased in the ghrelin-treated group. When the mice were administered D-Lys3-GHRP-6 (a ghrelin receptor antagonist), the decrease in the levels of some of the abovementioned indicators was insignificant; no statistically significant difference was observed in the levels of some of these indicators between the group treated with D-Lys3-GHRP-6 and the vehicle-treated group. These differences were also observed during histological and and survival analysis. Therefore, our results further confirm the protective role of ghrelin during intestinal I/R injury in mice.

mTOR is a type of atypical serine/threonine kinase which integrates various extracellular and intracellular signals, including metabolism, growth, survival, aging, synaptic plasticity, immunity and memory (10). The activation of the mTOR/p70S6K pathway is a critical event in the modulation of protein synthesis and the regulation of cell growth (37-39). However, certain studies have shown that phosphorylated forms of Akt and p70S6K are significantly decreased in transient focal cerebral ischemia, resulting in the suppression of the initiation step of protein synthesis and cell growth $(41,42)$. Thus, the activation of the mTOR/p70S6K pathway exerts a protective effect against ischemic brain injury $(12,13,43)$. In our study, the same phenomenon was observed in a mouse model of gut I/R; the phosphorylation levels of mTOR and p70S6K decreased in the tissue from the small intestine and pulmonary tissue following I/R. Recently, Aoyagi et al (46) used transgenic ( $\mathrm{Tg}$ ) mice with cardiac-specific overexpression of mTOR (mTOR-Tg mice) to examine I/R injury and found that mTOR overexpression inhibited necrosis during I/R injury. In our study, we observed that mTOR and p70S6K phosphorylation levels increased and that mucosal destruction, loss of villi, epithelial cell apoptosis in the small intestine and the disruption of lung architecture were alleviated in the animals administered ghrelin following gut I/R. These findings suggest that the activation of the mTOR/p70S6K signaling pathway inhibits cellular necrosis, and thus protects tissue architecture from destruction during gut I/R.

In addition to cell damage caused by ischemia and hypoxia, excessive and sustained inflammatory responses during reperfusion also play an important role in tissue damage. The expression of pro-inflammatory genes is regulated by transcriptional mechanisms. $\mathrm{NF}-\kappa \mathrm{B}$ is a critical transcription factor required for the maximal expression of several cytokines involved in the pathogenesis of acute lung injury and gut I/R injury (47,48). Moreover, mTOR negatively regulates the NF- $\kappa$ B pathway $(27,49)$. In monocytes and macrophages, mTOR inhibits NF- $\mathrm{B}$-dependent pro-inflammatory cytokine IL-12 production and activates STAT3-dependent anti-inflammatory IL-10 production $(27,44,45)$. Previous studies have shown that ghrelin inhibits leptin-induced pro-inflammatory cytokine (IL-1 $\beta$, TNF- $\alpha$ and IL-6) expression by human T cells and monocytes (20) and suppresses NF- $\kappa$ B activation in human endothelial cells (21). Recently, Aoyagi et al (46) reported that the expression of IL-6 and TNF- $\alpha$ in mTOR-Tg mouse hearts was lower than that in WT mouse hearts following cardiac I/R (46). These data indicate that the activation of the mTOR signaling pathway plays an anti-inflammatory role. Additionally, it has been reported that central ghrelin administration promotes a marked increase in the phosphorylated (active) form of mTOR and its downstream targets, pS6K1 and p6 in the arcuate nucleus of the hypothalamus (50). The data from the present study demonstrate that the intraperitoneal administration of ghrelin promotes the activity of the mTOR signaling pathway, inhibits some pro-inflammatory cytokine release and reduces neutrophil infiltration following gut I/R. Based on the above findings, it can be concluded that ghrelin promotes the activation of the mTOR/p70S6K signaling pathway and inhibits the $\mathrm{NF}-\kappa \mathrm{B}$ pathway in during inflammation; therefore, ghrelin reduces inflammatory responses, ameliorates organ damage and reduces mortality in the intestinal I/R injury model. Thus, ghrelin may be a potential therapeutic agent in various inflammatory disorders induced by gut I/R.

\section{Acknowledgements}

This study received funding from Wuhan Municipal Human Resources and Social Security Bureau (no. 2009-97). We thank Professor Feili Gong from the Department of Immunology, Tongji Medical College, Wuhan, China for his thoughtful scientific discussions. We also thank Professor Ping Wang from the Laboratory of Surgical Research, Feinstein Institute for Medical Research, Manhasset, NY, USA, for providing valuable advice in writing this manuscript.

\section{References}

1. Oldenburg WA, Lau LL, Rodenberg TJ, Edmonds HJ and Burger CD: Acute mesentericischemia: a clinical review. Arch Intern Med 164: 1054-1062, 2004.

2. Berlanga J, Prats P, Remirez D, Gonzalez R, Lopez-Saura P, et al: Prophylactic use of epidermal growth factor reduces ischemia/ reperfusion intestinal damage. Am J Pathol 161: 373-379, 2002.

3. Tendler DA: Acute intestinal ischemia and infarction. Semin Gastrointest Dis 14: 66-76, 2003.

4. Zhang $\mathrm{M}$ and Carroll MC: Natural antibody mediated innate autoimmune response. Mol Immunol 44: 103-110, 2007.

5. Leaphart CL and Tepas JJ III: The gut is a motor of organ system dysfunction. Surgery 141: 563-569, 2007.

6. Rotstein OD: Pathogenesis of multiple organ dysfunction syndrome: gut origin, protection, and decontamination. Surg Infect (Larchmt) 1: 217-225, 2000.

7. Tsang CK, Qi H, Liu LF and Zheng XF: Targeting mammalian target of rapamycin (mTOR) for health and diseases. Drug Discov Today 12: 112-124, 2007.

8. Weichhart T: Mammalian target of rapamycin: a signaling kinase for every aspect of cellular life. Methods Mol Biol 821: 1-14, 2012.

9. Yang $\mathrm{Q}$ and Guan KL: Expanding mTOR signaling. Cell Res 17: 666-681, 2012.

10. Zoncu R, Efeyan A and Sabatini DM: mTOR: from growth signal integration to cancer, diabetes and ageing. Nat Rev Mol Cell Biol 12: 21-35, 2011.

11. Hay $\mathrm{N}$ and Sonenberg N: Upstream and downstream of mTOR. Genes Dev 18: 1926-1945, 2004.

12. Koh PO: Melatonin prevents ischemic brain injury through activation of the mTOR/p70S6 kinase signaling pathway. Neurosci Lett 444: 74-78, 2008. 
13. Koh PO: Ginkgo biloba extract (EGb 761) prevents cerebral ischemia-induced p70S6 kinase and S6 phosphorylation. Am J Chin Med 38: 727-734, 2010.

14. Shi GD, OuYang Y.P, Shi JG, Liu Y, Yuan W and Jia LS: PTEN deletion prevents ischemic brain injury by activating the mTOR signaling pathway. Biochem Biophys Res Commun 404: 941-945, 2011.

15. Vigneron F, Dos Santos $\mathrm{P}$, Lemoine S, Bonnet M, Tariosse L, Couffinhal T, Duplaà C and Jaspard-Vinassa B: GSK-3 $\beta$ at the crossroads in the signalling of heart preconditioning: implication of mTOR and Wnt pathways. Cardiovasc Res 90: 49-56, 2011.

16. Kojima M, Hosoda H, Date Y, Nakazato M, Matsuo H and Kangawa $\mathrm{K}$ : Ghrelin is a growth-hormone-releasing acylated peptide from stomach. Nature 402: 656-660, 1999.

17. Arvat E, Di Vito L, Broglio F, Papotti M, Muccioli G, et al: Preliminary evidence that Ghrelin, the natural GH secretagogue (GHS)-receptor ligand, strongly stimulates GH secretion in humans. J Endocrinol Invest 23: 493-495, 2000.

18. Wu JT and Kral JG: Ghrelin: integrative neuroendocrine peptide in health and disease. Ann Surg 239: 464-474, 2004.

19. Cowley MA and Grove KL: Ghrelin - satisfying a hunger for the mechanism. Endocrinology 145: 2604-2606, 2004.

20. Dixit VD, Schaffer EM, Pyle RS, Collins GD, Sakthivel SK, Palaniappan R, Lillard JW Jr and Taub DD: Ghrelin inhibits leptin- and activation-induced pro-inflammatory cytokine expression by human monocytes and T cells. J Clin Invest 114 57-66, 2004

21. Li WG, Gavrila D, Liu X, Wang L, Gunnlaugsson S, Stoll LL, McCormick ML, Sigmund CD, Tang C and Weintraub NL: Ghrelin inhibits pro-inflammatory responses and nuclear factorkappaB activation in human endothelial cells. Circulation 109 2221-2226, 2004.

22. Konturek PC, Brzozowski T, Walter B, Burnat G, Hess T, Hahn EG and Konturek SJ: Ghrelin-induced gastroprotection against ischemia-reperfusion injury involves an activation of sensory afferent nerves and hyperemia mediated by nitric oxide. Eur J Pharmacol 536: 171-181, 2006.

23. Brzozowski T, Konturek PC, Sliwowski Z, Pajdo R, Drozdowicz D, Kwiecien S, Burnat G, Konturek S and Pawlik WW: Prostaglandin/cyclooxygenase pathway in ghrelininduced gastroprotection against ischemia-reperfusion injury. J Pharmacol Exp Ther 319: 477-487, 2006.

24. Brzozowski T, Konturek PC, Sliwowski Z, Drozdowicz D, Kwiecien S, Pawlik M, Pajdo R, Konturek SJ, Pawlik WW and Hahn EG: Neural aspects of ghrelin-induced gastroprotection against mucosal injury induced by noxious agents. J Physiol Pharmacol 57 (Suppl 6): S63-S76, 2006.

25. Pawlik MW, Obuchowicz R, Biernat J, Szczepanski W, Pajdo R, Kwiecień S, Brzozowski T, Konturek SJ and Pawlik WW: Effects of peripherally and centrally applied ghrelin in the pathogenesis of ischemia-reperfusion induced injury of the small intestine. J Physiol Pharmacol 62: 429-439, 2011.

26. Wu R, Dong W, Ji Y, Zhou M, Marini CP, Ravikumar TS and Wang P: Orexigenic hormone ghrelin attenuates local and remote organ injury after intestinal ischemia-reperfusion. PLoS One 3: e2026, 2008

27. Weichhart T, Costantino G, Poglitsch M, Rosner M, Zeyda M, et al: The TSC-mTOR signaling pathway regulates the innate inflammatory response. Immunity 29: 565-577, 2008.

28. Chiu CJ, McArdle AH, Brown R, Scott HJ and Gurd FN: Intestinal mucosal lesion in low-flow states. I. A morphological, hemodynamic, and metabolic reappraisal. Arch Surg 101: $478-483,1970$

29. Bachofen M and Weibel ER: Structural alterations of lung parenchyma in the adult respiratory distress syndrome. Clin Chest Med 3: 35-56, 1982.

30. Collard CD and Gelman S: Pathophysiology, clinical manifestations, and prevention of ischemia-reperfusion injury. Anesthesiology 94: 1133-1138, 2001.
31. Hattori N, Saito T, Yagyu T, Jiang BH, Kitagawa K, et al: GH, GH receptor, GH secretagogue receptor, and ghrelin expression in human T cells, B cells, and neutrophils. J Clin Endocrinol Metab 86: 4284-4291, 2001

32. Papotti M, Ghe C, Cassoni P, Catapano F, Deghenghi R, et al: Growth hormone secretagogue binding sites in peripheral human tissues. J Clin Endocrinol Metab 85: 3803-3807, 2000.

33. Shuto Y, Shibasaki T, Wada K, Parhar I, Kamegai J, et al: Generation of polyclonal antiserum against the growth hormone secretagogue receptor (GHS-R): evidence that the GHS-R exists in the hypothalamus, pituitary and stomach of rats. Life Sci 68 : 991-996, 2001

34. Wu R, Dong W, Cui X, Zhou M, Simms HH, et al: Ghrelin down-regulates pro-inflammatory cytokines in sepsis through activation of the vagus nerve. Ann Surg 245: 480-486, 2007.

35. Kojima $\mathrm{M}$ and Kangawa K: Ghrelin: structure and function. Physiol Rev 85: 495-522, 2005.

36. Wang G, Lee HM, Englander E and Greeley GH Jr: Ghrelin-not just another stomach hormone. Regul Pept 105: 75-81, 2002.

37. Kim DH and Sabatini DM: Raptor and mTOR: subunits of a nutrient-sensitive complex. Curr Top Microbiol Immunol 279: 259-270, 2004.

38. Montagne J, Stewart MJ, Stocker H, Hafen E, Kozma SC and Thomas G: Drosophila S6 kinase: a regulator of cell size. Science 285: 2126-2119, 1999.

39. Shima H, Pende M, Chen Y, Fumagalli S, Thomas G and Kozma SC: Disruption of the p70(s6k)/p85(s6k) gene reveals a small mouse phenotype and a new functional S6 kinase. EMBO J 17: 6649-6659, 1998.

40. Lawrence JC Jr and Brunn GJ: Insulin signaling and the control of PHAS-I phosphorylation. Prog Mol Subcell Biol 26: 1-31, 2001.

41. Janelidze S, Hu BR, Siesjö P and Siesjö BK: Alterations of Akt1 (PKBalpha) and p70(S6K) in transient focal ischemia. Neurobiol Dis 8: 147-154, 2001.

42. Mengesdorf T, Proud CG, Mies G and Paschen W: Mechanisms underlying suppression of protein synthesis induced by transient focal cerebral ischemia in mouse brain. Exp Neurol 177: 538-546, 2002.

43. Koh PO, Cho JH, Won CK, Lee HJ, Sung JH and Kim MO: Estradiol attenuates the focal cerebral ischemic injury through mTOR/p70S6 kinase signaling pathway. Neurosci Lett 436: 62-66, 2008

44. Weichhart T and Säemann MD: The multiple facets of mTOR in immunity. Trends Immunol 30: 218-226, 2009.

45. Baker AK, Wang R, Mackman N and Luyendyk JP: Rapamycin enhances LPS induction of tissue factor and tumor necrosis factor-alpha expression in macrophages by reducing IL-10 expression. Mol Immunol 46: 2249-2255, 2009.

46. Aoyagi T, Kusakari Y, Xiao CY, Inouye BT, Takahashi M, Scherrer-Crosbie M, Rosenzweig A, Hara K and Matsui T: Cardiac mTOR protects the heart against ischemia-reperfusion injury. Am J Physiol Heart Circ Physiol 303: H75-H85, 2012.

47. Wu R, Dong W, Zhou M, Zhang F, Marini CP, Ravikumar TS and Wang P: Ghrelin attenuates sepsis-induced acute lung injury and mortality in rats. Am J Respir Crit Care Med 176: 805-813, 2007.

48. Sato N, Moore FA, Smith MA, Zou L, Moore-Olufemi S, et al: Immune-enhancing enteral nutrients differentially modulate the early pro-inflammatory transcription factors mediating gut ischemia/reperfusion. J Trauma 58: 455-461, 2005.

49. Mendes Sdos S, Candi A, Vansteenbrugge M, Pignon MR, Bult H, Boudjeltia KZ, Munaut C and Raes M: Microarray analyses of the effects of NF-kappaB or PI3K pathway inhibitors on the LPS-induced gene expression profile in RAW264.7 cells: synergistic effects of rapamycin on LPS-induced MMP9overexpression. Cell Signal 21: 1109-1122, 2009.

50. Martins L, Fernández-Mallo D, Novelle MG, Vázquez MJ, Tena-Sempere M, Nogueiras R, López $M$ and Diéguez C: Hypothalamic mTOR signaling mediates the orexigenic action of ghrelin. PLoS One 7: e46923, 2012. 